\section{IMPACT OF CULTURAL VARIATION, GENDER AND AGE ON EXPERIENTIAL HOIME AND SCHOOL CLIMATE}

KEY WORDS: Cultural,

Cultural variation, School

Climate, Home Climate

\section{Ruchi Tewari*}

\section{Aradhana Shukla}

Department Of Psychology, Uttarakhand Open University, Haldwani, Uttarakhand, India. *Corresponding Author

Professor Department Of Psychology, Kumaun University Campus, Almora, Uttarakhand, India

The aim of this study was to find out the impact of gender, age and cultural variation was on experiential home and school climate. It was contended that variation in home and school climate would be influenced by variation in gender, age and cultural differences. Two hundred forty participants in the age range of late childhood and early adolescence served as participants and they were arranged according to the requirements of 3- way factorial design with three variations of culture, two types of gender, two types of climate variation and two levels of climate supportiveness. Home Environmental Scale and The School Climate Supportiveness Scale were used to assess the magnitude of home and school climate in participants. Data were analysed by 3-way ANOVA and it was found that

INTRODUCTION

The West might teach the East how to make a living, but it actually needs to ask the East to show the West how to live. (Tehyi Hsieh 1884-1972) Culture is literally how one lives and, by habit, is related to history. Le Roi Jones (1934-2014)

Culture is not just an ornament; it is the manifestation of the character of the country, and it is a strong instrument of character moulding at the same time. Correct living is the demise of civilization.W. Somerset Maugham (1874-1965)

Culture is a set of habits, attitudes and symbols that a broad number of people share and typically interact from one generation to the next. The term climate is regarded as a network of forces and variables surrounding, engulfing and playing on the person (Bloom, 1968). The term climate, in its usual sense, includes all the influences on development that come from outside the person, according to Stott (1974). The term environment has also been similarly described by Good (1973), Biswas and Agrawal (1971) and Wolman (1977). The home or family has also been identified by distinct authors. Murdock (1949) notes that the family is a social group characterized by shared residence, economic cooperation and reproduction, comprising both sexes who maintain a socially acceptable sexual partnership and one or more children, owning or accepting the sexual cohabiting pair. The International Dictionary of Education mentions that the family is a primary social group of parents.

School kids also face many obstacles that can lead to adverse effects and problem behaviors (Weissberg et al. 2003). The lack of happiness and joy has a big effect on the development of the personality of students and could affect their intellect, thinking skills, imagination, and educational achievements (Al-Yasin 2001).

Factors responsible for the interpretation of the school atmosphere as positive may be both intrinsic in the individual's perception and also in the unique characteristics of his environment. His value system, personality and needs are factors unique to the individual that affect the interpretation of the school environment. The behaviour of teachers and colleagues is a significant environmental factor linked to the perception of lack of help. The expectation of the instructor and the approval of the peer group were especially important in assessing the supportiveness of the perceived environment.

Although developmental processes in early childhood are embedded in the larger social, economic, and cultural environment (Bronfenbrenner \& Morris, 2006), with regard to the first years of life, the literature suggests that the family environment has a strong influence on the development of self-esteem (Harter, 2012a;Thompson, 2008).

The present study uses a measure of the home environment of the infant, covering parenting quality, cognitive stimulation, and physical home environment quality, and several theoretical perspectives indicate that parenting affects the development of self-esteem of children. The theory of attachment (Bowlby, 1969, 1973, 1980) suggests that the healthy attachment of a child to the caregiver contributes to the creation of a positive internal self-working model, that is, the representation that the self is important and deserves love and care from near others (Bretherton \& Munholland, 2008; Marvin \& Britner, 2008). Given that the most significant predictor of attachment stability is sensitive, trustworthy, and effective parenting activity by caregivers (Cassidy, 2008), attachment theory indicates that parenting has an effect on the development of self-esteem for children. In reality, research studies support the belief that healthy attachment to mothers and fathers promotes the self-esteem of young children (Verschueren \& Marcoen, 1999; Verschueren, Marcoen, \& Schoefs, 1996).

Symbolic interactionism also means that the child's interactions in the relationship with his or her parents affect the growth of self-esteem during early childhood (Cooley, 1902; Mead, 1934). This theory claims that self-knowledge has its roots in the social responses of others to themselves, like self-evaluation. Individuals therefore construe themselves on the basis of experiences of how others perceive them; to explain this phenomenon, Cooley (1902) coined the word looking-glass self. Given that a substantial portion of a child's social experiences occur with the primary caregiver during the first years of life, the theory of symbolic interactionism indicates that the consistency of parent-child interaction has a major effect on the early growth of self-esteem. Finally, the principle of sociometers (Leary, 2004, 2012; Leary \& Baumeister, 2000) also indicates that parental activity forms a child's developing self-esteem. According to this theory, selfesteem is part of a psychological mechanism that serves the function of tracking the need for social inclusion and that developed because it increased the chances of survival and unconsciousness of the person, his or her self-perceived probability of relationships being included (Leary \& Baumeister, 2000). Given the centrality of the parent-child relationship, the extent to which the relationship with the child is considered significant and important by his or her parents. More broadly, empirical research supports the belief that being respected by others leads to the growth of self-esteem (Gruenenfelder-Steiger, Harris, \& Fend, 2016; Reitz, MottiStefanidi, \& Asendorpf, 2016; Srivastava \& Beer, 2005) 
reproduction. Sociometer theory proposes that a person's self-esteem reflects-in an automatic

The aim of the study was to ascertain the impact of cultural variation, gender and age on experiential home and school climate. The objectives and hypotheses of the study were as follows:

- The first objective of this study was to find out the impact of cultural variation on home climate. It was hypothesized that variation in culture would cause variation on experiential home climate.

- The second objective of the study was to ascertain the relative efficacy of gender on home climate. It was contended that variation in gender would lay its impact on experiential home climate.

- The third objective of the study was aimed to explore the effect of chronological age on experiential home climate. It was thought that increase in age would cause variation in experiential home climate.

- The fourth objective of the investigation was to seek the dimension wise relationship in the home climate scale. It was thought that there would be a positive relationship between all the dimensions of home environmental scale.

- The fifth objective of the study was to find out the impact of cultural variation on school climate. It was hypothesized that variation in culture would cause variation on experiential school climate.

- The sixth objective of the study was to ascertain the relative efficacy of gender on school climate. It was contended that variation in gender would lay its impact on experiential school climate.

- The seventh objective of the study was aimed to explore the effect of chronological age on experiential school climate. It was thought that increase in age would cause variation in experiential school climate.

- The eighth objective of the investigation was to seek the dimension wise relationship in the school climate supportiveness scale. It was thought that there would be a positive relationship between all dimensions of school climate supportiveness scale.

\section{METHOD}

\section{SAMPLE}

Two hundred forty participants selected and served. They were arranged according to the requirement of three-way factorial design with three levels of cultural variation (Tharu, Buxa, General Kumauni), two gender (Boys and Girls), two types of climatic conditions (home and school) i.e. 20 participants in each cell. The design is presented in table 1.

Table 1 Schematic presentation of experimental design

$$
\text { A }
$$

$\begin{array}{lll}\text { A1 } & \text { A2 } & \text { A3 } \\ \text { B } & \text { B } & \text { B }\end{array}$

\begin{tabular}{lllllll} 
& B1 & B2 & B1 & B2 & B1 & B2 \\
C1 & 20 & 20 & 20 & 20 & 20 & 20 \\
C2 & 20 & 20 & 20 & 20 & 20 & 20 \\
\hline
\end{tabular}

\section{Legends}

A-Cultural Variation

Al-Tharu.

Bl-Boys

A2-Buxa

B2-Girls

A3-General Kumauni

\section{C-Climatic Condition}

Cl-Low level of climatic supportiveness

C2-High level of climatic supportiveness

\section{MEASURES}

In this study following measures were taken:
Home Environmental Scale: In order to assess the patterns of family climate the HES was employed. Constructed by Dhaundiyal(1993) this measure has 74 items and it deals with ten dimensions namely 1- Attention and care 2- facilities 3Impartiality 4- Parental approval of adolescents' activities 5Sharing of ideas 6-Trust 7-Confidence 8-Decision making 9Parental support and encouragement and 10- Harmony among family members. It is a questionnaire of true-false item. Thus, the score ranges between 74-148. Low scores indicate supportive family climate and high vice-versa. Split half reliability is .79 and test-retest reliability .70

The School Climate Supportiveness Scale: In order to measure the pattern of scholastic climate supportiveness in children a measure constructed by Shukla \& Mishra (1993) was used. This measure consists of forty-five items and deals with physical environment of the school, teacher's behaviour, teacher's expectancy, peer group behaviour and peer expectancy. The score range between 40-200. Low scores indicate supportive school climate and high scores vice-versa.

\section{RESULTS}

In this study an attempt was made to classify the subjects as low/high supportive for home/school on the basis of their scores on Home Environmental Scale and School Climate supportiveness Scale. Mean, SD and correlation analysed the obtained data. Findings were presented in five phases as they are given below:

\section{Phase I}

Frequency Distribution of Home Environmental Scale

Obtained data were separated by extreme group strategy method and frequency distribution was made of those participants who were selected for further studies. The frequency distribution is appeared in table 1 .

Table 2 Frequency Distribution of Scores of Home Environment Scale

\begin{tabular}{lc}
\hline Class Intervals & Frequency \\
\hline $140-149$ & \\
$130-139$ & 14 \\
$120-129$ & 23 \\
$110-119$ & 40 \\
$100-109$ & 30 \\
$90-99$ & 50 \\
$80-89$ & 37 \\
$70-79$ & 26 \\
& 20 \\
\hline
\end{tabular}

\section{Phase II}

Area Wise Analysis of Family Climate Scale

In order to measure the interaction pattern of family climate scale an area wise analysis of family climate scale was made. Data were pooled across all independent variables and mean values were computed.Findings are reported on table 3 .

\section{Table 3 Area Wise Analysis of Home Environment Scale:}

\section{S. N. Name of the Areas}

Mean Values

1. Attention and care

2. Facilities

3. Impartiality

Parental Approval of Adolescent Activities $\quad 15.85$

5. Sharing of Ideas

Trust

7. Confidence

8. Decision Making

10. Harmony among Family members 16.17 
Phase III Frequency Distribution of School Climate Supportiveness Scale

Similar to the HES data of school climate supportiveness scale was also analysed through frequency distribution and it is appeared in table 4 . Table shows that it is normally distributed at everywhere.

Table 4 Frequency Distribution of Scores on School Climate Supportiveness Scale

\begin{tabular}{lc}
\hline Class Intervals & Frequency \\
\hline $200-209$ & 3 \\
$190-199$ & 3 \\
$180-189$ & 5 \\
$170-179$ & 8 \\
$160-169$ & 8 \\
$150-159$ & 12 \\
$140-149$ & 22 \\
$130-139$ & 23 \\
$120-129$ & 26 \\
$110-119$ & 29 \\
$100-109$ & 29 \\
$80-99$ & 35 \\
$70-79$ & 14 \\
$60-69$ & 12 \\
$50-59$ & 14 \\
$40-49$ & 6 \\
& 10 \\
\hline
\end{tabular}

\section{Phase IV}

AreaWise Analysis of School Climate Supportiveness Scale

Moreover, an area wise analysis of school climate supportiveness scale was made. Data were pooled across all independent variables and it is appeared in table 5.

Table 5 Area Wise Analysis of School Climate Supportive ness Scale:

\begin{tabular}{llr}
\hline S.N. & Name of the Area (s) & Mean Values \\
\hline 1. & Physical Environment of school & 53.86 \\
2. & Teachers' behaviour & 30.99 \\
3. & Teachers' Expectancy & 45.07 \\
4. & Peer group behaviour & 35.00 \\
5. & Peer Expectancy & 24.95
\end{tabular}

\section{Phase V}

Correlational Analysis of Data: Dimensional Analysis of Family Climate and School Climate

In order to get the clear profile to data scores were subjected to correlation and coefficients are presented in inter correlation matrix and they are presented in table 6 (a) and (b)

\section{Table 6(a)}

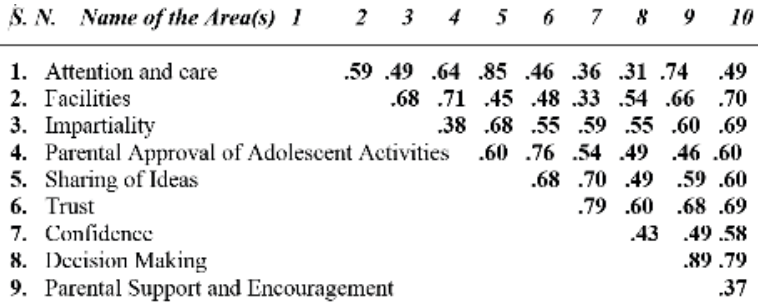

9. Parental Support and Encouragement

10. Harmony among Family members

Table reveals a close relationship the dimensions of home environment and

Table 6(b) Co-relational Analysis of family climate and school climate

\section{Name of the area(s)}

\begin{tabular}{lllll}
\hline 1. Physical Environment of school & .79 & .48 & .49 & .64
\end{tabular}

2. Teachers' behaviour

$\begin{array}{ll}.39 & .59 \\ 0 & .67\end{array}$

3. Teachers' Expectancy

$80 \quad 47$

4. Peer group behaviour

5. Peer Expectancy

Table reveals a close relationship the dimensions of home environment and school climate

|www.worldwidejournals.com |
Findings, is some, are as follows:

1. Data was normally distributed.

2. All dimensions were closely related.

3. Inter correlation was quite high.

\section{DISCUSSION}

Obtained data were analysed by means and correlation and they were discussed in terms of the importance of home and school climate. They are given below:

\section{Impartiality in Home}

'Impartiality' represents unbiased of children by elders of home parents tend to like one or other child in their family and behave in a positive way towards him or her. Special consideration to such a child often takes the form of suppression in negligence of other children's genuine needs and demands. It is likely that these neglected children become poorly adjusted and start viewing their parents in negative way.

\section{Parental Approval}

Approval of adolescents' various activities in home provides a measure of parental accepted of the various demands of adolescents. In home where various activities of adolescents are acceptance by their parents or rather encouraged by them, the adolescents feel more satisfied. This may lead towards better adjustment and attitude formation.

\section{Sharing of Ideas}

Home situation, in which several members remain interaction with each other, demands exchange of ideas, conflict and trust. Decision making is a normal phenomenon in which few members are sometimes involved in taking decisions. Involvement of every member of family in decision making, through continuous interaction in the form of expressed ideas and trust becomes a pre-requisite for healthy home environment.

\section{Parental Support and Care}

Parental support is an important factor. It was thought that running of children should be based on parental support and encouragement on the basis of which children should be developed properly.

\section{Harmony among Family Members}

Harmony among various family members is another important aspect of home environment. Parents and their children interact with each other in relation to their roles and personality needs. Sometimes, the quality of interactions remains mutually satisfying.

\section{School Climate}

School is the second major institution which provides opportunities to children for their growth and development. A child who comes to school brings with him his experiences obtained from his home. The home situation provides him opportunities to interact with a limited number of individuals. It also ascribes certain roles to him. In contrast, school is a large society where roles become more specific. In the place of parents, who guide children in their day-to-day behaviour in home, the teacher comes to play a significant part in the life of children. Peer group, study groups and co-curricular groups come into existence and the child becomes a member of one or more such groups within a large society. It is very much likely that experiences gained and behaviour patterns developed in the settings of school have a profound influence on personality adjustment and attitude towards authority of the children.

There are two factors that may be considered as responsible for the perception of the school climate. They are (i) interest in the perceiving individual and (ii) in the specific features of his environment. Factors with specific reference to the individual 
that influence perception of school climate are his value structure, personality and needs. An important environmental factor related to the perception of lack or support is the behaviour of teachers and peers. Teachers' expectancy and peer group acceptance have been found significant in determining the supportiveness of the perceived climate (Rosenthal, 1974; Zuckerman, 1979; Dweck \& Reppucci, 1973; Weiner, 1979).Teachers' expectations are related positively to the motivation and achievement of the student's belongingness to deprive.

\section{REFERENCES}

1. Al-Yasin, M. (2001). Happiness in school.Journal of Education., 33(1),67-87.

2. Biswas,A. \& Aggarwal, J.C.(1971). Encyclopedia Dictionary and Directory of Education, Vol.1, Academic Pub.,New Delhi.

3. Bloom, M. (1968). Stability and change in Human Characteristics, John-Willy \& Sons, New-York.

4. Bowlby, J. (1969). Attachment and loss:Vol. 1. Attachment. New York, NY: Basic Books.

5. Bowlby, J. (1973). Attachment and loss: Vol. 2. Separation: anxiety and anger. NewYork, NY:Basic Books.

6. Bowlby, J. (1980). Attachment and loss: Vol. 3. Loss: sadness and depression. NewYork, NY: Basic Books.

7. Bronfenbrenner, U., \& Morris, P. A. (2006). The bioecological model of human development. In R. M. Lerner (Ed.), Handbook of child psychology (6th ed.). Volume 1: Theoretical models of human development (pp. 793-828). New York, $\mathrm{NY}$ :Wiley.

8. Cooley, C.H. (1902). Human nature and the social order. New York, NY: Charles Scribner's Sons.

9. Good, C.V.(1973), Dictionary of Education,3 Ed., Mc-Graw Hill Co, New-York.

10. Gruenenfelder-Steiger, A. E., Harris, M. A., \& Fend, H. A. (2016). Subjective and objective peer approval evaluations and self-esteem development: $A$ test of reciprocal, prospective, and long-term effects. Developmental Psychology, 52, 1563-1577.

11. J. Cassidy \& P. R. Shaver (Eds.), Handbook of attachment: Theory, research, and clinical applications (pp. 269-294). New York, NY: Guilford.

12. Leary, M. R., \& Baumeister, R. F. (2000). The nature and function of self-esteem: Sociometer theory. In M. P. Zanna (Ed.), Advances in experimental social psychology (Vol.32,pp. 1-62). San Diego, CA:Academic Press.

13. Mead, G. H. (1934). Mind, self and society from the standpoint of a social behaviorist. Chicago: University of Chicago Press.

14. Murdock, G.P. (1949). Social structure.McMillan co.NewYork

15. Reitz, A. K., Motti-Stefanidi, F., \& Asendorpf, J. B. (2016). Me, us, and them: Testing sociometer theory in a socially diverse real-life context. Journal of Personality and Social Psychology, 110,908-920.

16. Rosenthal,R. (1973).The Pygmalion effect lines; Psychology Today. 7,36-63.

17. Srivastava, S., \& Beer,J. S. (2005). How self-evaluations relate to being liked by others: Integrating sociometer and attachment perspectives. Journal of Personality and Social Psychology, 89, 966-977.

18. Weiner, B. (1979). A theory motivation for some classroom experiences. Journal of Educational Psychology, 71,3-25.

19. Weissberg, R., Kumpfer, \& Seligman, M. (2003). Prevention that works for children and youth:An introduction. American Psychologist, 58, 425-432. 